\title{
Constitutive Activity of Nuclear Transcription Factor $\varkappa B$ is Observed in Follicular Lymphoma
}

\author{
Yuhko Suzuki, ${ }^{1,2)}$ Tsutomu Yoshida, ${ }^{3)}$ Ryouichi Horie, ${ }^{1)}$ Tomoko Tsuruta, ${ }^{3)}$ Tomiteru Togano, ${ }^{1)}$ \\ Manabu Ohsaka, ${ }^{1)}$ Koji Miyazaki, ${ }^{11}$ Mikio Danbara, ${ }^{1)}$ Shinichi Ohtani, ${ }^{2)}$ Isao Okayasu, ${ }^{3)}$ \\ and Masaaki Higashihara ${ }^{1)}$
}

Constitutive activity of nuclear transcription factor $\varkappa \mathrm{B}(\mathrm{NF}-\varkappa \mathrm{B})$ is observed in many pathological types of lymphoma that are associated with a poor clinical course. This suggests that $\mathrm{NF}-\varkappa \mathrm{B}$ and pathways involving NF- $\varkappa \mathrm{B}$ are possible targets for successfully treating lymphoma. We examined 28 lymph nodes from 28 patients in whom follicular lymphoma was diagnosed from 1996 to 2006 at our institution, which were formalin-fixed and paraffin-embedded. The specimens were stained with an antibody that could recognize activated $\mathrm{NF}-\varkappa \mathrm{B}$ and $\mathrm{p} 65$ to determine whether they were positive or negative for $\mathrm{NF}-\varkappa \mathrm{B}$ activation. The clinical courses of the 28 patients were then correlated with the results of the NF- $\varkappa \mathrm{B}$ staining. The 10 men and 18 women had a mean age of 57.3 years (range, 25-87 years). By follicular lymphoma grade, 10 patients had grade 1, 16 had grade 2, and 2 had grade 3a. Ten patients died due to lymphoma. NF- $\varkappa$ B was positive in 6 of the 28 cases. Analysis of the positive and negative staining groups while taking into account the clinical course, sex, age, grade of follicular lymphoma, prognostic index, CD10, CD23, Bcl-2, karyotype t(14;18), and survival showed that no significant differences. Six of the 28 lymph nodes (21.4\%) exhibited consistent NF- $\varkappa \mathrm{B}$ activity. Three of the eleven cases that transformed to aggressive lymphoma were positive for activated NF- $\varkappa \mathrm{B}$. Further research to clarify the significance of constitutive NF- $\varkappa \mathrm{B}$ activity in follicular lymphoma is therefore warranted. [J Clin Exp Hematopathol 50(1): 45-50, 2010〕

Keywords: nuclear transcription factor- $\varkappa \mathrm{B}$, follicular lymphoma, immunohistochemistry

\section{INTRODUCTION}

Follicular lymphoma (FL, previously called follicle center lymphoma) is the most common of the indolent non-Hodgkin lymphomas. It is defined as a lymphoma of follicle center Bcells (centrocytes and centroblasts) that has at least a partially follicular pattern. Follicular lymphoma comprises about $18 \%$ of adult non-Hodgkin lymphomas in $\mathrm{Japan}^{1}$ and $22 \%$ worldwide. $^{2}$

Clinically, most patients with FL have widespread disease at the time of diagnosis, including involvement of peripheral

\footnotetext{
Received: June 23, 2009

Revised : September 1, 2009

Accepted: September 25, 2009

${ }^{1)}$ Department of Hematology, Kitasato University School of Medicine, Sagamihara, Japan

${ }^{2)}$ Department of Transfusion and Cell Transplantation, Kitasato University School of Medicine, Sagamihara, Japan

${ }^{3)}$ Department of Pathology, Kitasato University School of Medicine, Sagamihara, Japan Address correspondence and reprint request to Yuhko Suzuki, M.D., Ph.D., Department of Hematology, Kitasato University School of Medicine, 1-15-1 Kitasato, Sagamihara 228-8555, Japan

E-mail : ysuzuki-hki@umin.ac.jp
}

and central lymph nodes and spleen; the bone marrow is involved in $40 \%$ of cases. Only $33 \%$ of patients are in stage I or II at the time of diagnosis. ${ }^{2}$ FL is generally associated with reasonably long survival, measured in years, even if initially untreated. $^{3}$ It is usually not curable with conventional treatment, which does not generally prolong overall survival. ${ }^{4}$ There is, however, increasing evidence that the availability of newer therapeutic options may be having a positive impact on improving failure-free survival, and perhaps even overall survival, in patients with advanced stage disease. . $^{3,5,6}$

The nuclear transcription factor $\varkappa \mathrm{B}(\mathrm{NF}-\varkappa \mathrm{B}) / \mathrm{Rel}$ family of proteins forms homo- and heterodimetric complexes that play a major role in controlling the expression of genes involved in immune, inflammatory, and acute phase responses. ${ }^{7} \mathrm{NF}-\varkappa \mathrm{B}$ is activated as part of the DNA damage response to ionizing radiation or some anti-cancer drugs and is thought to orchestrate a cell survival pathway that, together with the activation of cell cycle checkpoints and DNA repair, allows the cell in cases of limited damage to be restored. ${ }^{8}$ In several types of lymphoma, constitutive NF- $\varkappa \mathrm{B}$ activation is observed ; it can promote continuous lymphocyte proliferation and survival, and it has recently been recognized as a critical path genetic 
factor in lymphoma. ${ }^{9}$ However, constitutive activity of NF$\varkappa \mathrm{B}$ and its roles in FL have not been clarified and a correlation between NF- $\varkappa$ B in cases of FL and clinical and pathological implications has yet to be demonstrated.

\section{PATIENTS, MATERIALS AND METHODS}

\section{Patients' characteristics}

Twenty-eight patients with FL were enrolled in this study and their lymph nodes were biopsied at our hospital. Their characteristics are described in Table 1.

Table 1. Patients' characteristics

\begin{tabular}{lc}
\hline \multicolumn{1}{c}{ Clinical features } & Patients' characteristics \\
\hline Gender $(\mathrm{M}: \mathrm{F})$ & $10: 18$ \\
Age $(\mathrm{Y})$ & $25-87($ mean 57.3$)$ \\
Grade $(1: 2: 3 \mathrm{a})$ & $10: 16: 2$ \\
FLIPI (low $:$ int $:$ high) & $5: 7: 16$ \\
CD10 $(+:-: \mathrm{NR})$ & $19: 8: 1$ \\
CD23 $(+:-: \mathrm{NR})$ & $11: 7: 10$ \\
Light chain $(\varkappa: \lambda: \mathrm{NR})$ & $10: 14: 4$ \\
Karyotype & \\
t $(14 ; 18)$ & 12 \\
Normal & 4 \\
Others & 5 \\
N.R. & 7 \\
\hline
\end{tabular}

FLIPI, follicular lymphoma international prognostic index; N.R., not reported

\section{Patient samples}

Twenty-eight formalin-fixed paraffin-embedded tissue sections from 28 patients with FL were selected from the surgical pathology files of Kitasato University Hospital, Sagamihara for the immunohistochemical determination of active p65 (RelA).

\section{Immunohistochemical determination of activated p65 (Rel A)}

Staining was performed using a monoclonal mouse antihuman p65 (MAB3026, Chemicon International, Inc., Billerica, MA) that recognizes only the unbound, active form of p65 (RelA) dissociated from I $\varkappa$ Ba. Tissues were stained using Histofine ${ }^{\circledR}$ Simple Stain MAX-PO (Multi) secondary antibody (Nichirei Biosciences, Inc., Tokyo, Japan) in a $0.01 \% 3$, 3'-diaminobenzidine solution (brown) and counterstained with methyl green (green).

\section{Statistical analysis}

Data from patients and pathological samples were analyzed by t-tests, Fisher's test, and Kaplan-Meier analysis, using JMP Discovery Statistical Software (SAS Institute, Inc., Cary, NC) and are presented as means and standard errors. $P<0.05$ indicated a statistically significant difference.

\section{RESULTS}

\section{Positive rate of $\mathrm{NF}-\varkappa \mathrm{B}$}

As positive controls for activated p65, Hodgkin lymphoma and prostate cancer samples were used (Fig. 1a, 1b). Both Hodgkin lymphoma cells and prostate cancer cells showed strong immunopositivity. Six of the 28 pathological FL specimens stained positive for activated p65 (Fig. 1c, 1d). Positive cells were scattered throughout the follicles (Fig. 1e1h). Compared with the Hodgkin cells, their immunopositivity was weaker.

\section{Comparison between positive and negative cases}

The pathological findings of positive and negative cases were compared. FL grading $(1,2,3 \mathrm{a}$, or $3 \mathrm{~b}), \mathrm{CD} 10, \mathrm{CD} 23$, Bcl-2, and karyotype $t(14 ; 18)$ were analyzed. Results presented in Table 2 indicate that no differences between the two groups could be identified.

The clinical courses of positive and negative cases were compared, analyzing sex, mean age, Follicular Lymphoma International Prognostic Index (FLIPI), relapse-free survival after treatment (Fig. 2a), and overall survival (Fig. 2b), but no significant differences were found.

Table 2. Difference between NF- $\varkappa \mathrm{B}$ positive and negative

\begin{tabular}{lccc}
\hline \multicolumn{1}{c}{ Clinical features } & + & - & $\begin{array}{c}\text { Statistical } \\
\text { significance }\end{array}$ \\
\hline Patient number & 6 & 22 & \\
Gender $(\mathrm{M}: \mathrm{F})$ & $1: 5$ & $9: 13$ & N.S. \\
Age (mean) & 48.5 & 57.3 & N.S. \\
FLIPI (low : int : high) & $2: 0: 4$ & $4: 7: 11$ & N.S. \\
CD10 $(+:-)$ & $5: 1$ & $14: 7$ & N.S. \\
CD23 $(+:-)$ & $2: 1$ & $9: 6$ & N.S. \\
Bcl-2 $(+:-)$ & $6: 0$ & $21: 1$ & N.S. \\
Light chain $(\varkappa: \lambda)$ & $2: 2$ & $8: 12$ & N.S. \\
G-banding & & & \\
t(14; 18$)$ & 3 & 9 & N.S. \\
$\quad$ Normal & 1 & 3 & N.S. \\
$\quad$ Others & 2 & 8 & N.S., not sig- \\
Transform & 3 & 3 & \\
\hline FLIPI, follicular lymphoma international prognostic index ; &
\end{tabular}



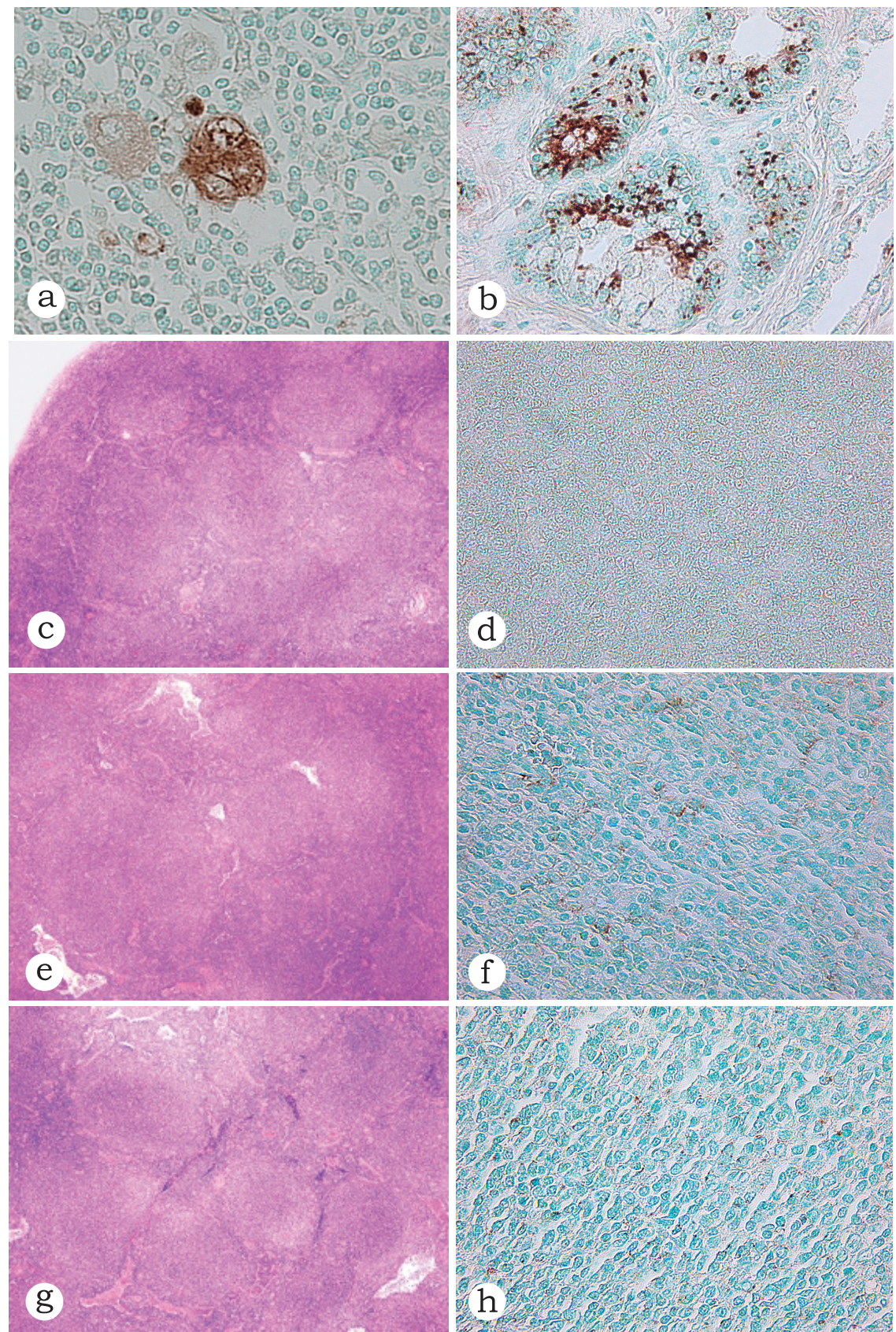

Fig. 1. Histological and immunohistochemical findings of resected lymph nodes. (1a) Hodgkin and Reed Sternberg cells showing strong immunopositivity for active p65 (relA). (1b) Prostate cancer cells showing strong immunopositivity for active p65 (relA). (1c) Follicular lymphoma (H\&E stain). (1d) Follicular lymphoma cells showing negative for active p65 (relA). (1e) Follicular lymphoma (H\&E stain). (1f) Follicular lymphoma cells showing weak immunopositivity for active p65 (relA). (1g) Follicular lymphoma (H\&E stain). (1h) Follicular lymphoma cells showing weak immunopositivity for active p65 (relA). Fig. $1 c$ and $1 d$ are taken from a same patient. Fig. $l e$ and $1 f$ are taken from the other same patients. The case of Fig. $1 g$ and $1 \mathrm{~h}$ are same as that of Fig. 1c. $(1 a),(1 b),(1 d),(1 f) \&(1 h)$, Counterstained with methyl green ; original magnification, $(1 a),(1 b) \&(1 d) \times 200 ;(1 c),(1 e) \&(1 g) \times 40 ;(1 f) \&(1 h) \times$ 400. 

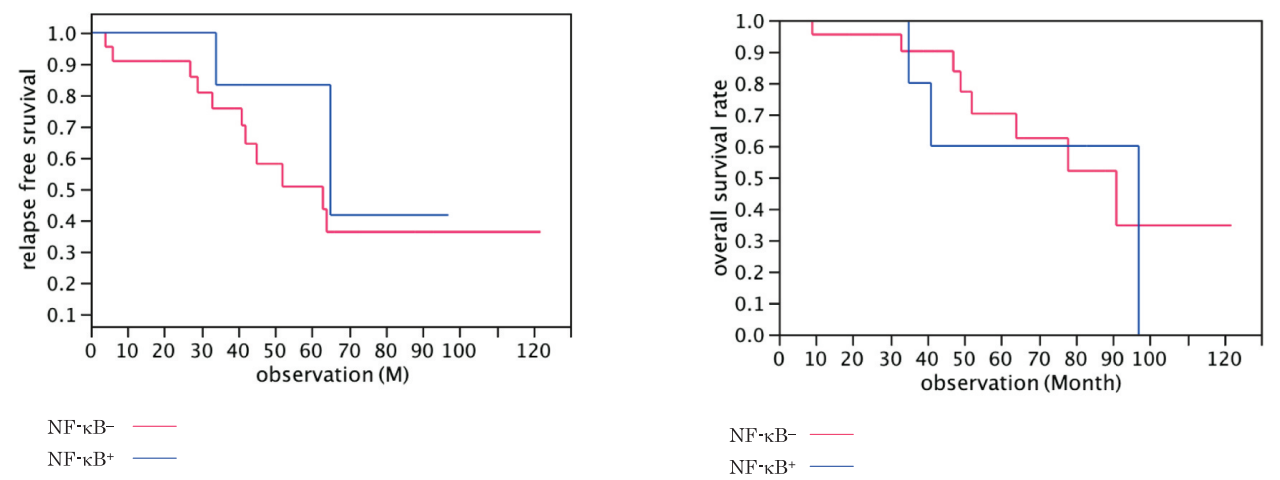

Fig. 2. Survival analysis. (2a) Relapse-free survival of positive and negative groups. There was no significant difference. (2b) Overall survival of positive and negative groups. There was no significant difference observed between the groups.

\section{DISCUSSION}

Because most studies have analyzed the activation of NF$\varkappa \mathrm{B}$ in FL using molecular genetic methods and constitutive activation of $\mathrm{NF}-\varkappa \mathrm{B}$ has been analyzed only infrequently, we assessed constitutive NF- $\varkappa \mathrm{B}$ activity using a histopathological approach. Six of the 28 FL cases (21.4\%) in our study exhibited constitutive NF- $\varkappa \mathrm{B}$ activity. The antibody used recognizes an epitope overlapping the nuclear location signal of the p65 subunit of NF- $\varkappa \mathrm{B}$ and selectively binds to its activated form. ${ }^{10}$ Therefore, the results confirm that constitutive NF$\varkappa \mathrm{B}$ activity exists in FL.

To clarify the significance of constitutive NF- $\varkappa$ B activity in FL, the association of NF- $\varkappa$ B positivity with various pathological and clinical prognostic factors was examined. Bcl-2 expression in the germinal center was observed in 21 of 22 cases. However, there were no statistical differences between the two groups. FL grade, ${ }^{11}$ FLIPI, ${ }^{12}$ and $\mathrm{CD} 10^{13}$ are widely thought to be prognostic factors in FL. FL tumors are graded on a scale from I to III and this grade appears to have some prognostic value. The FLIPI is based on an international study of long-term survival in more than 4,000 patients with FL and it is useful in assessing its prognosis. CD10 is a marker for germinal center B cells and it is generally expressed in FL cells. Karube et al. reported that patients with CD10-MUM1 ${ }^{+}$FL showed a relatively poor prognosis. ${ }^{13}$ However, in this study, no pathological and clinical information was found to be associated with constitutive NF- $\varkappa$ B activity in FL.

$t(14 ; 18)$-negative FL showed an increased level of NF- $x \mathrm{~B}$ activity within the subset identified by gene expression signature. ${ }^{14}$ In the present study, three of six cases that showed constitutive NF- $\varkappa \mathrm{B}$ activity were $\mathrm{t}(14 ; 18)$-negative, and the other three were $t(14 ; 18)$-positive ; thus, constitutive $\mathrm{NF}-\varkappa \mathrm{B}$ activity was observed for both $\mathrm{t}(14 ; 18)$-positive and negative groups. Why was constitutive NF- $\varkappa \mathrm{B}$ activity ob- served in $\mathrm{t}(14 ; 18)$-positive FL cases in our study? Constitutive NF- $\varkappa$ B activity may be induced by several things in lymphoma ${ }^{8,15-20}$ First of all, constitutive NF- $\varkappa$ B activity is induced by DNA damage, often from anti-cancer drugs or radiation therapy, ${ }^{8,15}$ but none of our patients with FL had been treated with either anti-cancer drugs or radiation therapy. In addition, deleterious mutations in the $\mathrm{I} \varkappa \mathrm{B} a$ gene have been reported in cases of Epstein-Barr virus-negative Hodgkin's lymphoma. These mutations may lead to nuclear translocation of NF- $\varkappa \mathrm{B}$ and transcriptional upregulation of its target genes. ${ }^{20,21}$ Mutation of the $\mathrm{I} \varkappa \mathrm{B} a$ gene may be a candidate for the activation of $\mathrm{NF}-x \mathrm{~B}$ in FL. Furthermore, microenvironments around the tumors have been a focus of some studies. In particular, macrophages that infiltrate tumors, called tumor-associated macrophages, secrete various cytokines ${ }^{16}$ and may induce constitutive NF- $\varkappa \mathrm{B}$ activity. Necrosis and hypoxia of tumors have been shown to induce the production of hydrogen peroxide and subsequent activation of NF- $x \mathrm{~B}$ in colon cancer. ${ }^{17}$ Cells around the lymphoma and its microenvironment are also candidates for causing $\mathrm{NF}-\varkappa \mathrm{B}$ activation in FL. As a cause of activation of NF- $\varkappa \mathrm{B}$ in B cell lymphoma, truncated p100 proteins with a partially deleted C-terminal ankyrin domain has been focused, but this is associated with the non-canonical pathyway, instead of the canonical pathway that we observed. ${ }^{18}$

Eleven cases transformed to aggressive lymphoma among 28 , six of which were re-biopsied after the transformation for immunostaining purposes. Three of these 6 transformed FL cases were positive for activated NF- $\varkappa \mathrm{B}$. Interestingly, one case that was negative at the onset of disease stained positive for $\mathrm{NF}-\varkappa \mathrm{B}$ only after transformation, while another two stained positive both before and after transformation. The case that was positive only after diffuse large B-cell lymphoma transformation was biopsied just after chemotherapy because this was a multi-drug-resistant case. Constitutive NF$\varkappa \mathrm{B}$ activity itself may have contributed to the resistance to 
chemotherapy or chemotherapy may have damaged the DNA of the lymphoma and induced constitutive NF- $\varkappa \mathrm{B}$ activity. The patient in this case died 5 months after the second biopsy. Because constitutive NF- $\varkappa$ B activity was observed in one case only after diffuse large B-cell lymphoma transformation, constitutive NF- $\varkappa$ B activity may be associated with the transformation of FL into an aggressive lymphoma. Because only a few transformed cases were examined in this study, analysis of additional cases is necessary to confirm the significance of these findings.

Only nodal FL cases were analyzed in this study. There are definitive differences between nodal and extranodal follicular lymphomas. Patients with extranodal FL may enter complete remission and they show a more favorable long-term prognosis compared to those with nodal FL. ${ }^{22}$ Therefore, analysis of NF- $\varkappa$ B activation in extranodal FL may be another means to identify a significant relationship between NF- $\varkappa \mathrm{B}$ activation and clinicopathological features.

Signaling pathways leading to constitutive NF- $\varkappa$ B activation in FL are currently unknown. The recently developed microarray technology allows large-scale parallel analyses of gene expression and permits simultaneous comparison of relative expression levels of thousands of genes in different cell types. ${ }^{23}$ FL have also been analyzed recently by this method. ${ }^{24,25}$ In FL, the activation of many molecules such as p38 MAPK, PLA2, platelet-derived growth factor receptor $\beta$ (PDGFR3), and Rab6 has previously been reported. ${ }^{26}$ Most of these molecules do not appear to be associated with NF- $x \mathrm{~B}$ activation.

Constitutive NF- $x \mathrm{~B}$ activity is observed in FL, but as of yet its significance is not fully understood. NF- $\varkappa \mathrm{B}$ and pathways involving $\mathrm{NF}-\varkappa \mathrm{B}$ are possible targets for successfully treating lymphoma. If constitutive $\mathrm{NF}-\varkappa \mathrm{B}$ activity can be stopped, then it is likely that lymphomas that depend on this activity can be successfully treated. Thus, the drug dehydroxymethylepoxyquinomicin, a novel NF- $\varkappa \mathrm{B}$ inhibitor, may be a successful treatment for lymphoma. ${ }^{27}$ Further research on the importance of $\mathrm{NF}-\varkappa \mathrm{B}$ in FL appears to be warranted.

\section{ACKNOWLEDGEMENT}

This study was supported in part by a grant from Keyakikai, which is the parents' association at Kitasato University Medical School. We would also like to thank all of our colleagues.

\section{REFERENCES}

1 Aoki R, Karube K, Sugita Y, Nomura Y, Shimizu K, et al. : Distribution of malignant lymphoma in Japan : analysis of 2260 cases, 2001-2006. Pathol Int 58 : 174-182, 2008

2 A clinical evaluation of the International Lymphoma Study Group classification of non-Hodgkin's lymphoma. The Non-Hodgkin's
Lymphoma Classification Project. Blood 89 : 3909-3918, 1997

3 Swenson WT, Wooldridge JE, Lynch CF, Forman-Hoffman VL, Chrischilles E, et al. : Improved survival of follicular lymphoma patients in the United States. J Clin Oncol 23 : 5019-5026, 2005

4 Hiddemann W, Buske C, Dreyling M, Weigert O, Lenz G, et al. : Current management of follicular lymphomas. $\mathrm{Br} \mathrm{J}$ Haematol 136: 191-202, 2007

5 Liu Q, Fayad L, Cabanillas F, Hagemeister FB, Ayers GD, et al. : Improvement of overall and failure-free survival in stage IV follicular lymphoma: 25 years of treatment experience at The University of Texas M. D. Anderson Cancer Center. J Clin Oncol $24: 1582-1589,2006$

6 Sacchi S, Pozzi S, Marcheselli L, Bari A, Luminari S, et al. : Introduction of rituximab in front-line and salvage therapies has improved outcome of advanced-stage follicular lymphoma patients. Cancer 109: 2077-2082, 2007

7 Doerre S, Mesires KP, Daley KM, McCarty T, Knoetig S, et al. : Reductions in $\mathrm{I} \varkappa \mathrm{B} \varepsilon$ and changes in $\mathrm{NF}-\varkappa \mathrm{B}$ activity during B lymphocyte differentiation. J Immunol 174 : 983-991, 2005

8 Janssens S, Tschopp J : Signals from within : the DNA-damageinduced NF- $\varkappa$ B response. Cell Death Differ 13: 773-784, 2006

9 Jost PJ, Ruland $\mathrm{J}$ : Aberrant NF- $\varkappa \mathrm{B}$ signaling in lymphoma : mechanisms, consequences, and therapeutic implications. Blood 109: 2700-2707, 2007

10 Zabel U, Henkel T, Silva MS, Baeuerle PA: Nuclear uptake control of NF- $\varkappa \mathrm{B}$ by MAD-3, an $\mathrm{I} \varkappa \mathrm{B}$ protein present in the nucleus. EMBO J 12 : 201-211, 1993

11 Martin AR, Weisenburger DD, Chan WC, Ruby EI, Anderson JR, et al. : Prognostic value of cellular proliferation and histologic grade in follicular lymphoma. Blood 85 : 3671-3678, 1995

12 Solal-Celigny P, Roy P, Colombat P, White J, Armitage JO, et al. : Follicular lymphoma international prognostic index. Blood 104: 1258-1265, 2004

13 Karube K, Guo Y, Suzumiya J, Sugita Y, Nomura Y, et al. : $\mathrm{CD}^{-} \mathrm{MUM}^{+}$follicular lymphoma lacks BCL2 gene translocation and shows characteristic biologic and clinical features. Blood 109: 3076-3079, 2007

14 Leich E, Salaverria I, Bea S, Zettl A, Wright G, et al. : Follicular lymphomas with and without translocation $t(14 ; 18)$ differ in gene expression profiles and genetic alterations. Blood 114 : 826-834, 2009

15 Laurent G, Jaffrezou JP : Signaling pathways activated by daunorubicin. Blood 98 : 913-924, 2001

16 Luo Y, Zhou H, Krueger J, Kaplan C, Lee SH, et al. : Targeting tumor-associated macrophages as a novel strategy against breast cancer. J Clin Invest 116 : 2132-2141, 2006

17 Mizukami Y, Jo WS, Duerr EM, Gala M, Li J, et al. : Induction of interleukin-8 preserves the angiogenic response in HIF-1adeficient colon cancer cells. Nat Med 11 : 992-997, 2005

18 Rayet B, Gelinas C: Aberrant rel/nfkb genes and activity in human cancer. Oncogene 18: 6938-6947, 1999

19 Doerre S, Corley RB : Constitutive nuclear translocation of NF$\varkappa \mathrm{B}$ in $\mathrm{B}$ cells in the absence of $\mathrm{I} \varkappa \mathrm{B}$ degradation. J Immunol 163 : 


\section{Suzuki Y, et. al.}

269-277, 1999

20 Cabannes E, Khan G, Aillet F, Jarrett RF, Hay RT : Mutations in the $\mathrm{I} \varkappa \mathrm{B} a$ gene in Hodgkin's disease suggest a tumour suppressor role for I $\varkappa \mathrm{B} a$. Oncogene 18 : 3063-3070, 1999

21 Thomas RK, Re D, Wolf J, Diehl V : Part I : Hodgkin's lymphoma - molecular biology of Hodgkin and Reed-Sternberg cells. Lancet Oncol 5 : 11-18, 2004

22 Goodlad JR, MacPherson S, Jackson R, Batstone P, White J : Extranodal follicular lymphoma : a clinicopathological and genetic analysis of 15 cases arising at non-cutaneous extranodal sites. Histopathology 44 : 268-276, 2004

23 Schena M, Shalon D, Davis RW, Brown PO : Quantitative monitoring of gene expression patterns with a complementary DNA microarray. Science 270: 467-470, 1995

24 Husson H, Carideo EG, Neuberg D, Schultze J, Munoz O, et al. :
Gene expression profiling of follicular lymphoma and normal germinal center B cells using cDNA arrays. Blood 99 : 282-289, 2002

25 Leich E, Hartmann EM, Burek C, Ott G, Rosenwald A : Diagnostic and prognostic significance of gene expression profiling in lymphomas. APMIS 115: 1135-1146, 2007

26 Elenitoba-Johnson KS, Jenson SD, Abbott RT, Palais RA, Bohling $\mathrm{SD}$, et al. : Involvement of multiple signaling pathways in follicular lymphoma transformation : p38-mitogen-activated protein kinase as a target for therapy. Proc Natl Acad Sci U S A 100 : 72597264, 2003

27 Horie R, Watanabe T, Umezawa K : Blocking NF- $\varkappa \mathrm{B}$ as a potential strategy to treat adult T-cell leukemia/ lymphoma. Drug News Perspect 19: 201-209, 2006 